\title{
Electrical response of ammonium-rich water ice
}

\author{
David E. STILLMAN, ${ }^{1}$ Joseph A. MacGREGOR, ${ }^{2}$ Robert E. GRIMM ${ }^{1}$ \\ ${ }^{1}$ Department of Space Studies, Southwest Research Institute, Boulder, CO, USA \\ E-mail: dstillman@boulder.swri.edu \\ ${ }^{2}$ Institute for Geophysics, John A. and Katherine G. Jackson School of Geosciences, University of Texas at Austin, \\ Austin, TX, USA
}

\begin{abstract}
The electrical properties of water ice impact the study of diverse frozen environments, in particular the radar sounding of ice masses. The high-frequency response of meteoric polar ice depends partly on the bulk concentration of ammonium $\left(\mathrm{NH}_{4}{ }^{+}\right)$, but the nature of this response has been unclear. Here we use broadband dielectric spectroscopy to investigate the electrical response of laboratoryfrozen solutions. By analyzing the relaxation frequency of these samples and its temperature dependence, we show that the mobility of Bjerrum D-defects formed in the ice lattice by ammonium is $1.4 \pm 0.8 \times 10^{-9} \mathrm{~m}^{2} \mathrm{~V}^{-1} \mathrm{~s}^{-1}$ at $-20^{\circ} \mathrm{C}$, or about an order of magnitude smaller than that of Bjerrum L-defects formed by chloride. However, co-substitution of both ions increases the ice-lattice solubility of chloride by a factor of $\sim 7$, causing an enhanced conductivity response due to greater concentrations of Bjerrum L-defects. Thus, despite its low mobility, ammonium can also affect the high-frequency electrical response of polar ice, but its covariance with chloride must be considered.
\end{abstract}

\section{INTRODUCTION}

For more than two decades now, polar ice cores have been logged electrically using various methods to record the chemical stratigraphy of ice (e.g. Wolff and others, 1997). High-frequency (HF) methods such as dielectric profiling (DEP) are sensitive to the bulk concentrations of latticesoluble acid $\left(\mathrm{H}^{+}\right)$, chloride $\left(\mathrm{Cl}^{-}\right)$and ammonium $\left(\mathrm{NH}_{4}^{+}\right)$ions (Moore and others, 1994a; Stillman and others, in press). As a result, an empirical relationship for the $\mathrm{HF}$ electrical conductivity $\sigma_{\infty}$ of polar ice at $-15^{\circ} \mathrm{C}$ now exists (Wolff and others, 1997):

$$
\sigma_{\infty}=9+4\left[\mathrm{H}^{+}\right]+1\left[\mathrm{NH}_{4}^{+}\right]+0.55\left[\mathrm{Cl}^{-}\right] .
$$

However, this relationship is based on the bulk concentration $\left(\mathrm{mol} \mathrm{L}^{-1}\right)$ of these impurities only, and not directly on the number of protonic point defects created in the ice lattice by each impurity, as implied by theory (Jaccard, 1964). Without adequate knowledge of specific model parameters (e.g. defect mobility and activation energy), efforts to reconcile this relationship with Jaccard theory remain incomplete (Moore and others, 1994a; Wolff and others, 1997). Thus, significant uncertainty remains in our ability to predict the HF conductivity of ice from its chemistry, which is of particular importance for efforts to infer impurity partitioning in ice from electrical logs (Stillman and others, in press), to quantify englacial dielectric attenuation (e.g. Corr and others, 1993; MacGregor and others, 2007) and to predict the performance of extraterrestrial orbital radar sounders (e.g. Blankenship and others, 2009).

Of the lattice-soluble ions common in polar meteoric ice, the electrical behavior of $\mathrm{NH}_{4}{ }^{+}$in ice is the most poorly understood. The covalent radius of $\mathrm{NH}_{4}{ }^{+}$allows it to substitute into the lattice to replace an $\mathrm{H}_{2} \mathrm{O}$ molecule. This replacement creates two Bjerrum D-defects (hereafter simply D-defects) in the ice lattice, which are hydrogen bonds that violate the Bernal-Fowler ice rules because they possess an $\mathrm{H}^{+}$ion at both ends (e.g. Petrenko and Whitworth, 1999). Moore and others (1994a) found that, for the Greenland Ice Core Project (GRIP) ice core from central Greenland, the DEP response to $\mathrm{NH}_{4}{ }^{+}$was about twice that per unit concentration of the response to $\mathrm{Cl}^{-}($Eqn (1)). They concluded that $\mathrm{NH}_{4}{ }^{+}$must be remarkably efficient at generating D-defects if their mobility is similar to extrinsic Bjerrum L-defects (hydrogen bonds with no $\mathrm{H}^{+}$ions) formed by $\mathrm{Cl}^{-}$. Previous measurements of frozen $\mathrm{NH}_{4}{ }^{+}$-doped solutions with lattice-insoluble anions found that $\mathrm{NH}_{4}{ }^{+}$ increases HF conductivity (Gross and Svec, 1997). Frozen $\mathrm{NH}_{4} \mathrm{~F}$ and $\mathrm{NH}_{4} \mathrm{Cl}$ solutions also have a much higher $\mathrm{HF}$ conductivity than similar solutions of $\mathrm{NaCl}$ or $\mathrm{HCl}$ (fluoride's electrical behavior in ice is similar to $\mathrm{Cl}^{-}$) (Gross and others, 1978; Gross and Svec, 1997). Despite this evidence, Petrenko and Whitworth (1999) concluded that the D-defect mobility is much less than L-defect mobility and should not affect the HF conductivity of ice, contrary to Eqn (1). However, they acknowledged that there is much uncertainty regarding D-defects and that additional data are needed.

Given the uncertainty surrounding a potentially important contributor to the HF conductivity of ice, here we revisit the electrical response of $\mathrm{NH}_{4}{ }^{+}$-rich ice using broadband dielectric spectroscopy (e.g. Grimm and others, 2008). A broadband approach is crucial, because it permits unambiguous determination of the dielectric relaxations associated with the HF response observed by Moore and others (1994a) using DEP, along with calculation of the key Jaccard parameters.

\section{THEORY AND EXPERIMENTAL APPROACH}

\section{Jaccard theory}

Jaccard (1964) developed a theoretical model of the electrical properties of ice that described how each individual type of protonic point defect influences the frequency and temperature dependence of the electrical properties. Extrinsic Bjerrum defects are formed by lattice-soluble impurities (e.g. $\mathrm{Cl}^{-}$and $\mathrm{NH}_{4}{ }^{+}$) that can replace an $\mathrm{H}_{2} \mathrm{O}$ molecule in the ice lattice. Jaccard theory does not consider the effect of any impurities excluded to grain boundaries or triple junctions. However, impurities excluded from the lattice do not typically affect the HF conductivity of ice 
(Stillman and others, in press), with important exceptions discussed below.

The conductivity $\sigma_{i}$ due to each defect type is the product of the defect's volumetric concentration $n_{i}$, mobility $\mu_{i}$ and effective charge $e_{i}$ :

$$
\sigma_{i}=n_{i} \mu_{i}\left|e_{i}\right| .
$$

The values of mobility and charge have been constrained for most defects (e.g. Camplin and others, 1978; Petrenko and Whitworth, 1999), but no value has been reported for the mobility of D-defects, $\mu_{\mathrm{D}}$.

The individual defect conductivities are summed by their defect group (ionic or Bjerrum). The HF conductivity of ice is the sum of these group conductivities. Thus, D-defects formed by $\mathrm{NH}_{4}{ }^{+}$could affect the HF conductivity if their mobility is non-negligible, if their defect concentration is large or if they increase substitution of other impurities into the lattice. The latter scenario in particular merits consideration, as Gross and others (1977) observed that $\mathrm{NH}_{4}{ }^{+}$ increased partitioning of $\mathrm{Cl}^{-}$into the lattice by a factor of $\sim 5$ compared to all other monovalent, mono-atomic cations (e.g. $\mathrm{H}^{+}, \mathrm{Na}^{+}$).

Jaccard theory assumes that ice possesses a Debye dielectric relaxation, i.e. the Cole-Cole distribution parameter $\alpha$ equals zero (Cole and Cole, 1941). However, the measured relaxation is rarely so ideal $(\alpha \approx 0.1)$. In a Debye relaxation, HF conductivity plateaus, whereas for a nonDebye relaxation HF conductivity continues to increase slightly with frequency. We therefore analyze our results in terms of the relaxation time $\tau$ rather than the frequencydependent HF conductivity. When Bjerrum defects dominate, $\tau$ is defined as

$$
\tau=\frac{G e_{\mathrm{DL}}^{2}}{8 \sqrt{3} r_{\mathrm{OO}} k_{\mathrm{B}} T \sigma_{\mathrm{DL}}}
$$

where $G \approx 3, e_{\mathrm{DL}}$ is the charge of either a D- or L-defect $\left(6.088 \times 10^{-20} \mathrm{C}\right), r_{\mathrm{OO}}$ is the mean distance between oxygen ions in the ice lattice $\left(2.764 \times 10^{-10} \mathrm{~m}\right), k_{\mathrm{B}}$ is the Boltzmann constant $\left(1.38 \times 10^{-23} \mathrm{~J} \mathrm{~K}^{-1}\right), T$ is temperature, and $\sigma_{\mathrm{DL}}$ is the sum of the D- and L-defect conductivities (e.g. Petrenko and Whitworth, 1999). Relaxation time is related to relaxation frequency $f_{\mathrm{r}}$ as $f_{\mathrm{r}}=1 / 2 \pi \tau$.

If a single defect type is dominant, the temperature dependencies of both the HF conductivity and the relaxation time are equivalent to the temperature dependence of that defect's mobility, because both defect charge and concentration are temperature-independent (Eqn (2)). This temperature dependence is used to discriminate between defect types. At low extrinsic Bjerrum defect concentrations and/or high temperatures $\left(>-40^{\circ} \mathrm{C}\right)$, the activation energy of intrinsic L-defects is high $(\sim 0.58 \mathrm{eV})$. At low to moderate concentrations of extrinsic L-defects or low temperatures $\left(<-40^{\circ} \mathrm{C}\right)$, their activation energy is $\sim 0.19-0.24 \mathrm{eV}$ (Takei and Maeno, 1987; Grimm and others, 2008). In this regime, the HF conductivity is proportional to the defect concentration (Eqn (2)). For high extrinsic L-defect concentrations (up to the solubility limit) and/or very low temperatures, the activation energy increases to $0.294 \mathrm{eV}$ because these defects begin to interfere with one another (Grimm and others, 2008). No activation energy for extrinsic D-defects has been reported previously.

Because of the high activation energy of intrinsic Ldefects, even in extremely pure ice extrinsic L-defects control the relaxation time at low temperatures. Kawada (1978) measured the dielectric properties of ice frozen from triply deionized water and observed this transition between intrinsic and extrinsic L-defects near $-50^{\circ} \mathrm{C}$ (Fig. 1). Assuming $\mu_{\mathrm{exL}}=2 \times 10^{-8} \mathrm{~m}^{2} \mathrm{~V}^{-1} \mathrm{~s}^{-1}$ at $-20^{\circ} \mathrm{C}$ and adjusting the mobility to $-50^{\circ} \mathrm{C}$ with an unsaturated L-defect activation energy of $0.232 \mathrm{eV}$ (Kawada, 1978; Grimm and others, 2008), we find that the residual extrinsic L-defect concentration is equivalent to a $\mathrm{Cl}^{-}$lattice concentration of $0.6 \pm 0.2 \mu \mathrm{M}$.

\section{Sample preparation and dielectric measurements}

$\left(\mathrm{NH}_{4}\right)_{2} \mathrm{SO}_{4}$ solutions were chosen to determine unambiguously the electrical response to defects formed by $\mathrm{NH}_{4}{ }^{+}$only, because the covalent radius of $\mathrm{SO}_{4}{ }^{2-}$ is too large to substitute for $\mathrm{H}_{2} \mathrm{O}$ in the ice lattice and form protonic point defects. Conversely, measurement of frozen $\mathrm{NH}_{4} \mathrm{Cl}$ solutions permits investigation of the possible co-substitution of both ions.

The sample holder was placed into an insulated, temperature-adjustable freezer for the dielectric measurements. $\left(\mathrm{NH}_{4}\right)_{2} \mathrm{SO}_{4}(0.1,1.0$ and $2.9 \mathrm{M})$ and $\mathrm{NH}_{4} \mathrm{Cl}(0.1,1.0$ and $4.4 \mathrm{M}$ ) solutions were frozen directly onto the electrodes. The laboratory-frozen samples were cylindrical disks $3 \mathrm{~cm}$ in diameter and $0.6 \mathrm{~cm}$ thick and frozen slowly to produce polycrystalline ice free of bubbles and cracks. Solutions were held at $2 \mathrm{~K}$ below their freezing point for 1 hour to initialize crystallization and then $10 \mathrm{~K}$ below their freezing point for an additional 2 hours to crystallize any meta-stable water. The sample was reheated and annealed at $2 \mathrm{~K}$ below their freezing point for 3 hours. This process was then repeated at the sample's eutectic temperature. The lowest measurement temperature was reached slowly $(0.1 \mathrm{~K}$ $\mathrm{min}^{-1}$ ) to impede crack formation. Measurements during subsequent warming were typically made at $5 \mathrm{~K}$ intervals, while stabilizing temperature to within $0.2 \mathrm{~K}$ for at least 30 min. See Grimm and others (2008) for additional details regarding sample preparation.

We measured the broadband $\left(10^{-2}-10^{6} \mathrm{~Hz}\right)$ dielectric properties of these ices at various temperature ranges between $-145^{\circ} \mathrm{C}$ and $-1{ }^{\circ} \mathrm{C}$. We used a three-electrode sample holder with a Solartron 1260A impedance analyzer and a Solartron 1296A dielectric interface. The complex impedance was converted into complex dielectric permittivity using the electrode geometry, and the Cole-Cole parameters describing each observed dielectric relaxation were modeled by nonlinear curve fitting, following Grimm and others (2008).

The lattice concentration of the laboratory-frozen ice samples is inevitably much less than the concentration of the solution from which they were frozen. For example, Gross and others (1977) reported a partition coefficient of $1.4 \times 10^{-2}$ for slowly frozen $\mathrm{NH}_{4} \mathrm{Cl}$ solutions with the rest excluded to grain boundaries or inclusions. At higher concentrations the ice lattice saturates in defects formed by $\mathrm{NH}_{4}{ }^{+}$and/or $\mathrm{Cl}^{-}$and yet larger fractions of the initial concentration are excluded from the lattice. In the presence of any cation other than $\mathrm{NH}_{4}{ }^{+}$, the solubility limit of $\mathrm{Cl}^{-}$in ice is $200 \pm 100 \mu \mathrm{M}$ (Seidensticker, 1972; Gross and others, 1977; Domine and others, 1994; Moore and others, 1994b). However, the solubility limits of either $\mathrm{NH}_{4}{ }^{+}$alone or $\mathrm{Cl}^{-}$in the presence of $\mathrm{NH}_{4}{ }^{+}$have not yet been reported. Gross and others (1977) inferred the solubility limits of $\mathrm{HCl}$ and $\mathrm{NaCl}$ accurately by observing when the partition coefficient of those impurities decreased despite increasing solution concentration. Similarly, we infer from measurements of the relaxation time of $\mathrm{NH}_{4} \mathrm{Cl}$-doped ice by Gross and others 

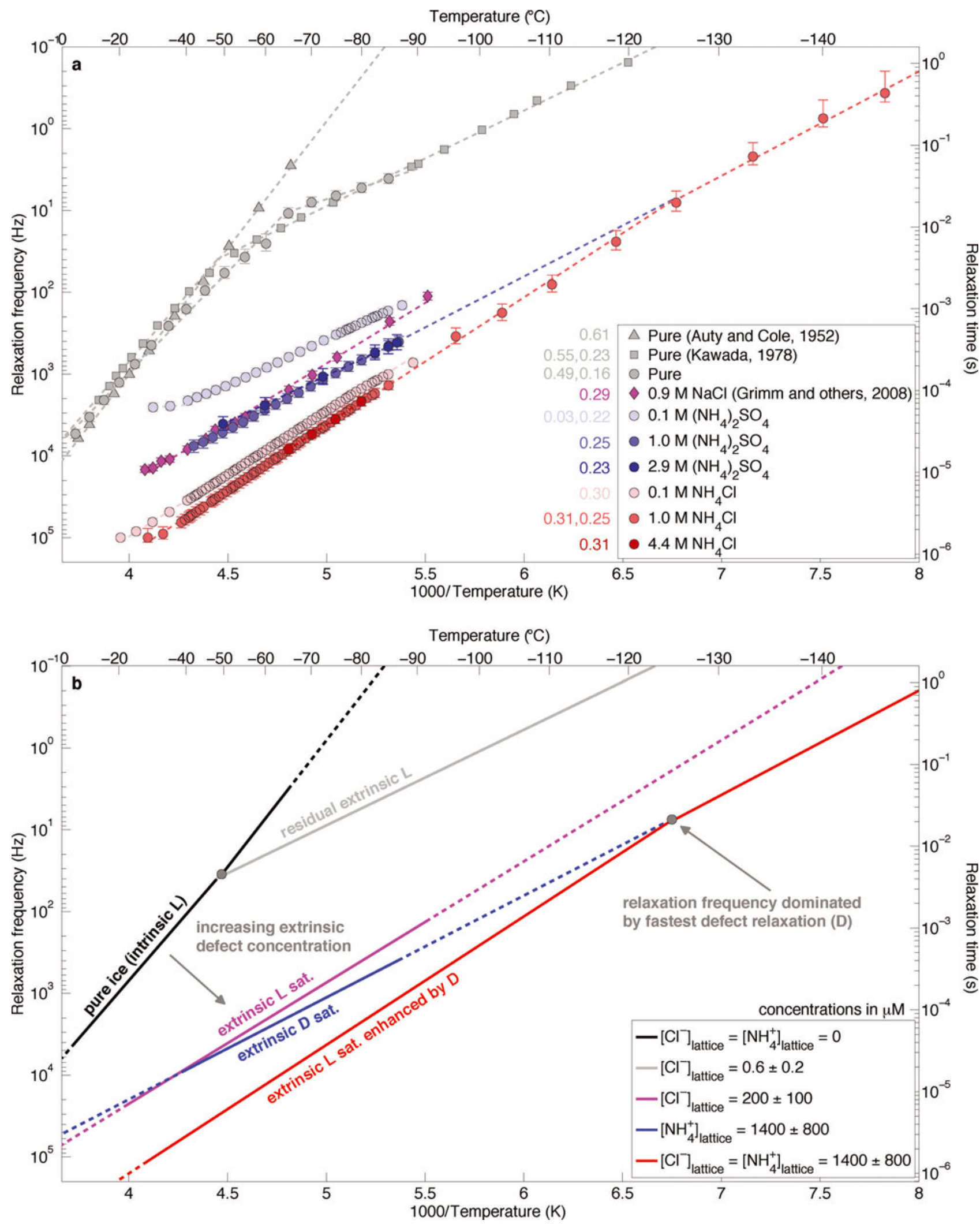

Fig. 1. (a) Temperature dependence of the relaxation frequency of $\mathrm{NH}_{4}{ }^{+}$-rich laboratory-frozen ices. Initial solution concentrations of the laboratory-frozen samples (which are also the bulk ice concentration) are given in the legend. Error bars represent the 95\% confidence intervals for each value, estimated using $\chi^{2}$ distributions. Activation energies $(\mathrm{eV})$ are shown in the same colour adjacent to the legend. Uncertainties for these values are typically $<0.01 \mathrm{eV}$. Where two activation energies are given, the temperature dependence is fit across two adjacent temperature ranges, and the high temperature value is given first. (b) Schematic interpretation of observations.

(1977) (their fig. 11) that the solubility limit of $\mathrm{NH}_{4} \mathrm{Cl}$ in ice is $400-2000 \mu \mathrm{M}$. Because the defects formed by $\mathrm{Cl}^{-}$are expected to co-substitute with those formed by $\mathrm{NH}_{4}{ }^{+}$, we infer that this solubility limit is also that of $\mathrm{NH}_{4}{ }^{+}$alone.
The HF conductivity of ice is affected by excluded impurities under two conditions only: (1) The bulk salt concentration is sufficiently high (typically $>10^{-3} \mathrm{M}$ ) and the temperature is above the eutectic temperature so that 
Table 1. Summary of the Jaccard parameters derived in this study. See table 6.4 of Petrenko and Whitworth (1999) (p. 154) for Jaccard parameters of other protonic point defects

Lattice composition

Relaxation properties at $T_{0}\left(-20^{\circ} \mathrm{C}\right)$

Description

Concentration

$\tau_{0}$

E

$10^{-6} \mathrm{M}$

$10^{23} \mathrm{~m}^{-3}$

$10^{-6} \mathrm{~s}$

$\mathrm{eV}$

$10^{-8} \mathrm{~m}^{2} \mathrm{~V}^{-1} \mathrm{~s}^{-1}$

$\mathrm{Cl}^{-}$saturated $(\mathrm{L})$

$\mathrm{Cl}^{-}$saturated with $\mathrm{NH}_{4}{ }^{+}$present (L)

$200 \pm 100$

$2.4 \pm 1.2$

$6.0 \pm 0.3$

$1400 \pm 800$

$17 \pm 8$

$17 \pm 8$

$0.84 \pm 0.3$

$5.9 \pm 0.3$

0.294

0.312

0.250

$1.0 \pm 0.5$

$1.0 \pm 0.5$

$0.14 \pm 0.08$ electrolytic conduction through the interconnected brine channels becomes non-negligible (Grimm and others, 2008). (2) The salt-hydrate volume fraction is greater than a few percent, so soluble impurities also create extrinsic defects in the salt hydrates and hence a dielectric relaxation that is faster than that of the ice lattice (Grimm and others, 2008). The first scenario is avoided by analysis of data at temperatures well below the eutectic temperatures of the frozen solutions $\left(-9^{\circ} \mathrm{C}\right.$ and $-5^{\circ} \mathrm{C}$ for $\mathrm{NH}_{4} \mathrm{Cl}$ and $\left(\mathrm{NH}_{4}\right)_{2} \mathrm{SO}_{4}$, respectively). The second scenario is avoided by using the lowest solution concentration with a defect-saturated lattice, so that the possible presence of salt-hydrate relaxation is minimized, but this relaxation can also be detected using Cole-Cole modeling.

\section{RESULTS}

\section{Relaxation-frequency behaviour}

The relaxation frequency of the $\left(\mathrm{NH}_{4}\right)_{2} \mathrm{SO}_{4}$-doped samples is more than an order of magnitude larger than that of classic measurements of pure laboratory-frozen ice, even at the lowest solution concentration (Fig. 1a). This observation demonstrates clearly that $\mathrm{NH}_{4}{ }^{+}$affects the HF conductivity of ice, independent of other lattice-soluble ions, by increasing the relaxation frequency. Because the relaxation frequency did not change significantly between the frozen 1.0 and $2.9 \mathrm{M}$ original liquid concentration of $\left(\mathrm{NH}_{4}\right)_{2} \mathrm{SO}_{4}$ $\left(\left[\left(\mathrm{NH}_{4}\right)_{2} \mathrm{SO}_{4}\right]_{\text {liq }}\right)$ solutions, the solubility limit (or saturation concentration) of D-defects for our freezing procedure must lie at $1.0 \mathrm{M}$, or below, times an unknown partition coefficient. The temperature dependence of the relaxation frequency of the D-defect-dominated samples $(0.247 \mathrm{eV})$ is lower than that of L-defect-saturated ice frozen from $\mathrm{Cl}^{-}$-rich solutions (0.294 eV; Grimm and others, 2008), suggesting that significant $\mathrm{Cl}^{-}$contamination did not occur. Note that the formal uncertainties for these activation energies are generally $<0.01 \mathrm{eV}$.

The relaxation frequency of the $\mathrm{NH}_{4} \mathrm{Cl}$-doped samples is much larger than that of either $\left(\mathrm{NH}_{4}\right)_{2} \mathrm{SO}_{4}$ - or $\mathrm{NaCl}$-doped samples that are saturated in Bjerrum defects generated by $\mathrm{NH}_{4}{ }^{+}$or $\mathrm{Cl}^{-}$, respectively (Fig. 1a). These observations are consistent with previous measurements of frozen $\mathrm{NH}_{4} \mathrm{~F}$ and $\mathrm{NH}_{4} \mathrm{Cl}$ solutions (Gross and others, 1978; Gross and Svec, 1997). Above $-125^{\circ} \mathrm{C}$, the temperature dependence of the relaxation frequency of both saturated $\mathrm{NH}_{4} \mathrm{Cl}$-doped samples is $0.310 \mathrm{eV}$. This value is close to that of $\mathrm{Cl}^{-}$-saturated ice, suggesting that the mechanism causing the higher relaxation frequencies is simply increased solubility of $\mathrm{Cl}^{-}$ into the ice lattice due to co-substitution of $\mathrm{NH}_{4}{ }^{+}$. Below $-125^{\circ} \mathrm{C}$, the relaxation-frequency temperature dependence decreases to $0.253 \mathrm{eV}$, indicating that D-defects have a higher mobility than L-defects at low temperatures.

\section{Jaccard analysis}

We now use Jaccard theory to determine the mobility of D-defects, but first we verify that our data are consistent with earlier experiments that determined the mobility of L-defects. Because the solubility limit of L-defects formed by $\mathrm{Cl}^{-}$is well constrained, but that of D-defects formed by $\mathrm{NH}_{4}{ }^{+}$is poorly constrained, the mobility of the latter cannot be determined from the $\left(\mathrm{NH}_{4}\right)_{2} \mathrm{SO}_{4}$ experiments alone.

To calculate defect mobilities, we assume that the lattice is saturated with the relevant defect once the relaxation frequency plateaus despite increasing solution concentration. As explained above, in the presence of any cation other than $\mathrm{NH}_{4}{ }^{+}$, the solubility limit of $\mathrm{Cl}^{-}$is $200 \pm 100 \mu \mathrm{M}$ and the activation energy of the saturated L-defect mobility is $0.294 \mathrm{eV}$ (Grimm and others, 2008). Combining Eqns (2) and (3) yields $\mu_{\mathrm{L}}=1.0 \pm 0.5 \times 10^{-8} \mathrm{~m}^{2} \mathrm{~V}^{-1} \mathrm{~s}^{-1}$ at $-20^{\circ} \mathrm{C}$ (Table 1; see Appendix for detailed analysis), which is slightly lower than that synthesized by Petrenko and Whitworth (1999) $\left(2 \times 10^{-8} \mathrm{~m}^{2} \mathrm{~V}^{-1} \mathrm{~s}^{-1}\right)$. This difference could be due to experimental error or the L-defect mobility may depend on concentration, as does the activation energy. The latter behavior also occurs for ionic defects (Camplin and others, 1978).

The increase in the relaxation frequency of the $\mathrm{NH}_{4} \mathrm{Cl}$ saturated ice is equivalent to a factor of $7.2 \pm 2.5$ increase in the solubility of extrinsic L-defects formed by $\mathrm{Cl}^{-}$. Thus, the solubility limit of $\mathrm{Cl}^{-}$when it co-substitutes into the ice lattice with $\mathrm{NH}_{4}{ }^{+}$is $1400 \pm 800 \mu \mathrm{M}$ (Table 1). This solubility limit is within the range for $\mathrm{NH}_{4} \mathrm{Cl}(400-2000 \mu \mathrm{M})$ that we inferred earlier from the reanalysis of the partitioning data of Gross and others (1977).

The temperature dependence of the $1.0 \mathrm{M}\left[\mathrm{NH}_{4} \mathrm{Cl}\right]_{\text {liq }}$ sample changes below $-125^{\circ} \mathrm{C}$ from the $\mathrm{L}$-defect value $(0.310 \mathrm{eV})$ to the saturated $\mathrm{D}$-defect value inferred from the 1.0 and $2.9 \mathrm{M}\left[\left(\mathrm{NH}_{4}\right)_{2} \mathrm{SO}_{4}\right]_{\text {liq }}$ samples $(0.253 \mathrm{eV})$. This temperature, where $\mathrm{D}$-defects begin to dominate the relaxation, matches that predicted by extrapolation of the temperature dependence of the $\left(\mathrm{NH}_{4}\right)_{2} \mathrm{SO}_{4}$ samples (Fig. 1b). This observation indicates that the lattice concentration of D-defects in the saturated $\left(\mathrm{NH}_{4}\right)_{2} \mathrm{SO}_{4}$-doped samples is equal to that in the saturated $\mathrm{NH}_{4} \mathrm{Cl}$ samples. Because $\mathrm{NH}_{4}^{+}$and $\mathrm{Cl}^{-}$ions co-substitute and these ions form two D- and two L-defects, respectively, we assume that their defect concentrations are equal in the frozen $\mathrm{NH}_{4} \mathrm{Cl}$ solutions. Thus, the co-substitution of $\mathrm{Cl}^{-}$does not increase the solubility limit of $\mathrm{NH}_{4}{ }^{+}$, and the solubility limit of $\mathrm{NH}_{4}{ }^{+}$ with or without co-substituted $\mathrm{Cl}^{-}$is also $1400 \pm 800 \mu \mathrm{M}$. We then calculate the saturated mobility of D-defects to be 
$1.4 \pm 0.8 \times 10^{-9} \mathrm{~m}^{2} \mathrm{~V}^{-1} \mathrm{~s}^{-1}$ at $-20^{\circ} \mathrm{C}$ (Table 1; Appendix), or about an order of magnitude lower than that of L-defects at the same temperature.

\section{DISCUSSION AND CONCLUSIONS}

We determined the D-defect mobility and its temperature dependence at saturation for the first time. We further constrained the solubility limit of co-substituted $\mathrm{NH}_{4}{ }^{+}$and $\mathrm{Cl}^{-}$in ice to be $1400 \pm 800 \mu \mathrm{M}$. There can now be no doubt that D-defects are mobile in the lattice and that they can affect the HF conductivity of ice significantly, not only through their relatively small mobility, but also through the associated co-substitution of $\mathrm{Cl}^{-}$.

These results explain the vexing ammonium-DEP relationship observed by Moore and others (1994a) and show that the relationship between ice chemistry and DEP is not yet fully understood. For example, if we consider a $10 \%$ increase in $\sigma_{\infty}$ at $-15^{\circ} \mathrm{C}$, which is large enough to distinguish the DEP response to $\mathrm{NH}_{4}{ }^{+}$, then following Eqns (1), (2) and (A1) and the Jaccard parameters determined above, a $10 \%$ increase in $\sigma_{\infty}$ is equivalent to an $\mathrm{NH}_{4}{ }^{+}$lattice concentration of $7.0 \mu \mathrm{M}$. Critically, this calculation assumes that no $\mathrm{Cl}^{-}$-produced $\mathrm{L}$ defects are present, so that $\mathrm{NH}_{4}{ }^{+}$is balanced by another anion. The $\mathrm{Cl}^{-}$lattice concentration necessary to produce an equivalent increase in $\sigma_{\infty}$ is only $0.50 \mu \mathrm{m}$. Alternatively, if both $\mathrm{NH}_{4}{ }^{+}$and $\mathrm{Cl}^{-}$co-substitute into the lattice equally, then the lattice concentration of both ions necessary to produce a $10 \%$ increase in $\sigma_{\infty}$ is slightly lower $(0.46 \mu \mathrm{M})$.

Bulk $\mathrm{NH}_{4}{ }^{+}$concentrations greater than $7 \mu \mathrm{M}$ occur in $<0.02 \%$ of all samples measured in the Greenland Ice Sheet Project 2 (GISP2) ice core (Yang and others, 1997), which is similar to the GRIP ice core from which the empirical $\sigma_{\infty}$ relationship (Eqn (1)) was derived. Hence, it is unlikely that the GRIP DEP response to $\mathrm{NH}_{4}{ }^{+}$was detected due to that impurity's HF response alone. The background value of bulk $\mathrm{Cl}^{-}$concentration from the same core (GISP2) is $\sim 0.3 \mu \mathrm{M}$, and bulk $\mathrm{Cl}^{-}$and $\mathrm{NH}_{4}{ }^{+}$concentrations are not well correlated (Yang and others, 1997). Therefore, the DEP response is most likely not due to D-defects formed by $\mathrm{NH}_{4}{ }^{+}$, but rather due to the increase in L-defects formed by the increased lattice concentration of $\mathrm{Cl}^{-}$. This increased concentration occurs because the $\mathrm{NH}_{4}{ }^{+}$cation allows increased partitioning of the $\mathrm{Cl}^{-}$anion into the lattice by co-substitution.

We suggest that the covariance of these two impurities $\left(\mathrm{Cl}^{-}\right.$ and $\mathrm{NH}_{4}^{+}$) must be taken into account both when interpreting DEP logs of ice cores and when modeling englacial radar attenuation for ice masses that contain non-negligible concentrations of both impurities. $\mathrm{NH}_{4}{ }^{+}$concentrations are about an order of magnitude higher in the Greenland ice sheet than in Antarctica, while $\mathrm{Cl}^{-}$concentrations can be high in both ice sheets, particularly in coastal regions (Legrand and Mayewski, 1997). Thus, these complications in both interpretation and prediction of the HF conductivity of ice are likely of greater concern for Greenland and the coastal regions of Antarctica.

\section{ACKNOWLEDGEMENTS}

This work was supported by NASA's Planetary Geology and Geophysics Program (NNX10AJ65G, NNX08AM92G). We thank the editor and two anonymous reviewers for comments that improved the manuscript significantly.

\section{REFERENCES}

Blankenship DD, Young DA, Moore WB and Moore JC (2009) Radar sounding of Europa'a subsurface properties and processes: the view from Earth. In Pappalardo RT, McKinnon WB and Khurana KK eds. Europa. University of Arizona Press, Tucson, AZ

Camplin GC, Glen JW and Paren JG (1978) Theoretical models for interpreting the dielectric behaviour of HF-doped ice. J. Glaciol., 21(85), 123-141

Cole KS and Cole RH (1941) Dispersion and absorption in dielectrics. I. Alternating current characteristics. J. Chem. Phys., 9(4), 341-351 (doi: 10.1063/1.1750906)

Corr H, Moore JC and Nicholls KW (1993) Radar absorption due to impurities in Antarctic ice. Geophys. Res. Lett., 20(11), 1071-1074 (doi: 10.1029/93GL01395)

Domine F, Thibert E, Van Landeghem F, Silvente $\mathrm{E}$ and Wagnon $\mathrm{P}$ (1994) Diffusion and solubility of $\mathrm{HCl}$ in ice: preliminary results. Geophys. Res. Lett., 21(7), 601-604 (doi: 10.1029/94GL00512)

Grimm RE, Stillman DE, Dec SF and Bullock MA (2008) Lowfrequency electrical properties of polycrystalline saline ice and salt hydrates. J. Phys. Chem., 112(48), 15382-15390 (doi: 10.1021/jp8055366)

Gross GW and Svec RK (1997) Effect of ammonium on anion uptake and dielectric relaxation in laboratory-grown ice columns. J. Phys. Chem. B, 101(32), 6282-6284 (doi: 10.1021/ jp963213c)

Gross GW, Wong PM and Humes K (1977) Concentration dependent solute redistribution at the ice-water phase boundary. III. Spontaneous convection. Chloride solutions. J. Chem. Phys., 67(11), 5264-5274 (doi: 10.1063/1.434704)

Gross GW, Hayslip IC and Hoy RN (1978) Electrical conductivity and relaxation in ice crystals with known impurity content. J. Glaciol., 21(85), 143-160

Jaccard C (1964) Thermodynamics of irreversible processes applied to ice. Phys. Kondens. Mater., 3(2), 99-118 (doi: 10.1007/ BF02422356)

Kawada S (1978) Dielectric anisotropy in ice Ih. J. Phys Soc. Jpn, 44(6), 1881-1886

Legrand M and Mayewski P (1997) Glaciochemistry of polar ice cores: a review. Rev. Geophys., 35(3), 219-243 (doi: 10.1029/ 96RG03527)

MacGregor JA, Winebrenner DP, Conway H, Matsuoka K, Mayewski PA and Clow GD (2007) Modeling englacial radar attenuation at Siple Dome, West Antarctica, using ice chemistry and temperature data. J. Geophys. Res., 112(F3), F03008 (doi: 10.1029/2006JF000717)

Moore JC, Reid AP and Kipfstuhl J (1994a) Microstructure and electrical properties of marine ice and its relationship to meteoric ice and sea ice. J. Geophys. Res., 99(C3), 5171-5180 (doi: 10.1029/93JC02832)

Moore JC, Wolff EW, Clausen HB, Hammer CU, Legrand MR and Fuhrer K (1994b) Electrical response of the Summit-Greenland ice core to ammonium, sulphuric acid, and hydrochloric acid. Geophys. Res. Lett., 21(7), 565-568 (doi: 10.1029/94GL00542)

Petrenko VF and Whitworth RW (1999) Physics of ice. Oxford University Press, Oxford

Seidensticker RG (1972) Partitioning of $\mathrm{HCl}$ in the water-ice system. J. Chem. Phys., 56(6), 2853-2857 (doi: 10.1063/1.1677617)

Stillman DE, MacGregor JA and Grimm RE (in press) The role of acids in electrical conduction through ice. J. Geophys. Res. (doi: 10.1029/2012JF002603)

Takei I and Maeno N (1987) Electric characteristics of point defects in $\mathrm{HCl}$-doped ice. J. Phys. IV [Paris], 48(C1), 121-126 (doi: 10.1051/jphyscol:1987118)

Wolff EW, Miners WD, Moore JC and Paren JG (1997) Factors controlling the electrical conductivity of ice from the polar regions - a summary. J. Phys. Chem., 101(32), 6090-6094 (doi: 10.1021/jp9631543) 
Yang Q, Mayewski PA, Twickler MS and Whitlow S (1997) Major features of glaciochemistry over the last 110,000 years in the Greenland Ice Sheet Project 2 ice core. J. Geophys. Res., 102(D19), 23 289-23 299 (doi: 10.1029/97JD00737)

\section{APPENDIX}

The extrinsic L- and D-defect mobilities are calculated by first finding the volumetric defect concentration $n$ and then using the modeled data to find the relaxation time $\tau$ :

$$
\begin{gathered}
n=1000 A p S, \\
\tau=\tau_{0} \exp \left[\frac{E}{k}\left(\frac{1}{T_{0}}-\frac{1}{T}\right)\right],
\end{gathered}
$$

where $A$ is the Avogadro constant $\left(6.0221 \times 10^{23} \mathrm{~mol}^{-1}\right)$, $p=2$ is the number of defects per substitution for either $\mathrm{Cl}^{-}$ or $\mathrm{NH}_{4}{ }^{+}, S$ is the defect's molarity in the lattice, $\tau_{0}$ is the relaxation time at a reference temperature $\left(T_{0}=-20^{\circ} \mathrm{C}\right)$, and $E$ is the activation energy. The factor of 1000 in Eqn (A1) arises from the conversion between standard units used for $S$ (L) and $n\left(\mathrm{~m}^{3}\right)$. We calculated $n_{\mathrm{L}}^{\mathrm{NH}_{4} \mathrm{Cl}_{\text {sat }}}$ and thus $S$ for $\mathrm{NH}_{4}{ }^{+}$in our frozen solutions at temperatures above $-125^{\circ} \mathrm{C}$ as

$$
n_{\mathrm{L}}^{\mathrm{NH}_{4} \mathrm{Cl}_{\text {sat }}}=\frac{\tau_{\mathrm{L}}^{\mathrm{Cl}_{\text {sat }}^{-}}}{\tau^{\mathrm{NH}_{4} \mathrm{Cl}_{\text {sat }}}} n_{\mathrm{L}}^{\mathrm{Cl}_{\text {sat }}^{-}}=7.2 \pm 2.5 n_{\mathrm{L}}^{\mathrm{Cl}_{\text {sat }}^{-}} .
$$

The mobility is then calculated by combining Eqns (2) and (3):

$$
\mu=\frac{G e_{\mathrm{DL}}}{8 r_{\mathrm{OO}} k_{\mathrm{B}} T \tau n \sqrt{3}} .
$$

Table 1 summarizes the results of these calculations. 